\title{
Investigation of the effects of childhood sexual abuse on disease severity and cognitive functions in borderline personality disorder
}

\author{
Sakir Gica ${ }^{1 \oplus}$, Bahar Kaplan $^{2 \oplus}$, Ayse Terzi Atar ${ }^{3 \oplus}$, Medine Yazici Gulec ${ }^{4 \oplus}$, Huseyin Gulec ${ }^{5}$ \\ ${ }^{1}$ Necmettin Erbakan University, Meram Faculty of Medicine, Department of Psychiatry, Konya - Turkey \\ ${ }^{2}$ Sivas Provincial Health Directorate, Sivas Numune Hospital, Department of Psychiatry, Sivas - Turkey \\ ${ }^{3}$ University of Health Sciences Turkey Istanbul Umraniye Training and Research Hospital, Department of Psychiatry, Istanbul - Turkey \\ ${ }^{4}$ University of Health Sciences Turkey Istanbul Erenkoy Mental Health and Neurological Disease Education and Research Hospital, \\ Department of Psychiatry, Department of Psychotherapeutic Intervention, Istanbul - Turkey \\ ${ }^{5}$ University of Health Sciences Turkey Istanbul Erenkoy Mental Health and Neurological Disease Education and Research Hospital, \\ Department of Psychiatry, Istanbul - Turkey
}

\begin{abstract}
Objective: The aim of this study is to investigate the effects of childhood sexual abuse (CSA) on decision-making, facial emotion recognition, and clinical presentation of borderline personality disorder (BPD). In addition, it was examined whether certain cognitive impairments could be worsened by the presence of CSA.

Method: Eighteen sexually abused BPD patients, 18 patients with BPD without CSA, and 35 healthy controls were included in the study. The Borderline Personality Inventory (BPI) and the Childhood Trauma Questionnaire (CTQ) were administered to BPD patients. The Cambridge Neuropsychological Test Automated Battery (CANTAB), which is used to examine decision-making and emotional recognition, was administered to the patients and healthy controls.

Results: In the emotion recognition test, the mean percentages of correct fear recognition were $33.5 \pm 14.6$ for patients with CSA, 25.89 \pm 9.8 for patients without CSA, 26.8 \pm 7.4 for healthy controls. The mean percentage of correct fear recognition was higher in patients with CSA than in the other groups. There was no difference in the correct recognition of other emotions between the groups. The probability of risking a $10 \%$ chance of winning in patients with/without CSA and healthy controls averaged were $0.71 \pm 0.26,0.33 \pm 0.28$, and $0.25 \pm 0.20$ respectively. The average risk-taking propability in patients with CSA was significantly higher than in other groups. A significant correlation was identified between BPI and CTQ scores.
\end{abstract}

Conclusion: The present study supports the fact that CSA has significant effects on the clinical presentation and neurocognitive profiles of BPD.

Keywords: Borderline personality disorder, decision-making, emotion recognition, childhood sexual abuse

\section{INTRODUCTION}

The lifetime prevalence of borderline personality disorder (BPD) has been estimated as $5.9 \%$ in the general population (1) and is quite common in psychiatric samples (15-40\%) (2). BPD, as a chronic psychiatric condition, is characterized by high levels of impulsivity and affective instability, along with marked

How to cite this article: Gica S, Kaplan B, Terzi Atar A, Yazici Gulec M, Gulec H. Investigation of the effects of childhood sexual abuse on disease severity and cognitive functions in borderline personality disorder. Dusunen Adam The Journal of Psychiatry and Neurological Sciences 2021;34:141-150.

Correspondence: Sakir Gica, Necmettin Erbakan University, Meram Medical Faculty, Department of Psychiatry, Konya - Turkey 
difficulty in initiating and managing interpersonal relationships (3). Given these characteristics, BPD is associated with major individual and social costs (4). Patients with BPD differ substantially from the general population with respect to all costs involved. The annual direct health care costs and indirect costs in terms of productivity loss are 16 times higher in patients with BPD than in individuals without BPD (5). The severity of BPD requires particular attention in diagnostic procedures and early therapeutic interventions because currently available pharmacotherapy alone is not sufficient to manage the complexity of BPD. The complex nature of individuals with BPD has made many physicians reluctant to treat them (6). Many studies have been conducted to better understand the etiology as well as to establish an explanatory model of this common disease with limited treatment options. Numerous informative reviews have generally supported the importance of considering childhood trauma (e.g. emotional, physical, sexual abuse, neglect) as a prominent contributor to BPD risk (7). However, in recent meta-analyses, it has been reported that subtypes of early life trauma may be more associated with different psychiatric diseases, personality disorders and clinical conditions observed in adulthood (8). In this context, many studies have evaluated the association between childhood sexual abuse (CSA) and BPD diagnosis (9). CSA was reported to be prevalent in 16 to $86 \%$ of adult patients with $\mathrm{BPD}$ (10). In three systemic reviews and meta-analyses, a statistically significant and consistent relationship was found between the development of CSA and BPD $(8,11,12)$. In adult patients with BPD, CSA was found to be associated with multiple hospitalizations, adult suicidal tendency, the overall severity of BPD, and general severity of psychosocial impairment (13). However, the mechanisms by which childhood maltreatment and CSA impair and lead to adverse clinical effects have not been clarified. Nevertheless, identifying these mechanisms may be important in establishing a tailored pharmacotherapy targeting specific symptom clusters and thereby improving the relevant aspects of the clinical manifestation.

Impairment in cognitive functions is thought to be central to the pathophysiology of BPD (14-16). Therefore, it is important to examine cognitive functions in BPD patients with CSA. Nevertheless, the small sample sizes of studies and the differences in research methodologies may lead to conflicting results. In addition, it should be taken into consideration that comorbid psychiatric conditions are more common in
BPD. For this reason, meta-analyses are important to ensure access to the accurate information. Recent metaanalyses have suggested that one of the cognitive domains with the most consistent deficits is the area of decision-making (17). Impaired decision-making may explain why BPD patients prefer high reward situations. These patients are unable to use deterrent motivation in situations where there are obvious long-term harmful consequences such as impulsive spending, sexual behavior, and substance abuse. In fact, even if these patients receive explicit feedback on the negative consequences of their behavior, they continue to practice impaired decision-making (18).

One of the important cognitive areas emphasized in BPD patients is the ability to recognize facial emotion. Although most of the studies have shown inconsistent findings, patients with BPD were seen to misclass neutral or ambiguous facial expressions in a negative way consistently (19-21). Inaccurate negative interpretation of facial emotional expressions of others will likely lead to behavioral and emotional consequences, including rejection or perceiving others as malicious. As a result, a diminished emotion recognition skills may cause a significant decrease in the social functioning of BPD patients in the real world (20). To our knowledge, no studies conducted in the published literature so far have evaluated the effects of sexual trauma on the emotion recognition ability of patients with BPD.

Trauma is a broad term used for many negative life events. The current study focuses on CSA, which is more easily identifiable, more precise, and also an important part of the trauma. The effects of CSA on cognition in BPD have not been examined to date. Therefore, our study aimed to investigate the effects of CSA on cognitive functions and the clinical presentation of BPA patients, as well as to evaluate whether certain cognitive disorders observed in BPD worsen with exposure to CSA. This study emphasizes the importance of questioning childhood maltreatment in clinical evaluations. We hypothesized that individuals exposed to CSA would make more risky decisions and have difficulty in emotion recognition. Moreover, childhood traumas may aggravate the clinical presentation of BPD.

\section{METHOD}

\section{Participants}

The study has a prospective case-control design. Statistical analysis of data obtained from a project examining clinical features and cognitive functions in 
BPD was used as the starting point of the present study. In the project, we aimed to address the ongoing deficiencies in the diagnostic validity of BPD and to increase its validity. The areas examined include: 1 . The extent to which particular clinical entities represent the disorder, such as suicide attempts, impulsivity, or dissociative symptoms that occurred in BPD; 2. The effects of factors that are important in disease development such as childhood traumas; 3 . The capacity of cognitive functions such as planning, visual memory, decision-making, sustaining attention, flexible thinking, and emotion recognition in BPD patients. The latter functions have standardized measurement tools to represent these dimensions. Forty-five patients diagnosed with BPD according to the Diagnostic and Statistical Manual of Mental Disorders, fourth edition (DSM-IV), and 35 healthy volunteers were included in the project. The healthy control group was selected among relatives of healthcare professionals who did not have any psychiatric complaints or a history of psychiatric diseases. The diagnosis of BPD was carried out with a standardized clinical interview by a psychiatrist outside the research team. All participants were informed about the research and each agreed to provide informed consent to participate in the study. After the data collection was completed, the BPD patients were divided into two groups according to their childhood sexual trauma histories. As stated in the Turkish version of the Childhood Trauma Questionnaire (CTQ), while patients with a sexual abuse score of 6 and above were categorized as patients exposed to sexual abuse, patients with a score of 5 or less were categorized as patients not having exposed to sexual abuse. In order to neutralize the confounding effects of factors such as education level, age, and gender, which are known to have an impact on cognitive functions, the groups were matched with these variables. Therefore, 9 patients with CSA were excluded from the study. Three patient groups matched for age, educational level, and gender were obtained. These included 18 patients with having exposure to sexual abuse, 18 patients with having no exposure to sexual abuse, and 35 healthy controls. The lack of psychopathology was confirmed by applying the Structured Clinical Interview for DSM-IV Axis I Disorders (SCID-I) and the Structured Clinical Interview for DSM-III-R Personality Disorders (SCIDII) on all participants. Exclusion criteria included patients and healthy volunteers who: 1 . were less than 18 years old or older than 65 years; 2 . were lack of enough education that might hinder the evaluation of the instructions; 3 . had clear mental retardation and cognitive decline, 4 . were diagnosed with a serious general medical condition according to the interview, 5. were diagnosed with alcohol/substance use disorder, 5. had comorbid psychiatric disorders. Ethical approval for the study was obtained from the University of Health Science Turkey, Erenkoy Clinical Research Ethics Committee (IRB Date/Number: 01.06.2015/11). The power of the study was calculated as 0.85 by evaluating the effect size as 0.40 , $\alpha$-error as 0.05 , and sample size as 72 with $G$ Power (3.1.9.2.).

\section{Procedure}

In the current study, the subjects were recruited from a specialized public psychotherapy center, where longterm care and supervision were provided by experienced healthcare professionals. One of the important features of our study is that the diagnosis of BPD was made in a psychotherapy center, which provides the possibility of long-term follow-up of the outpatients. This ensured a high diagnostic reliability. Patients with BPD were evaluated in terms of Borderline Personality Inventory (BPI) and other comorbid psychiatric conditions. The Verbal Memory Processes Test (VMPT) and Cambridge Neuropsychological Test Automated Battery (CANTAB) were administered to the patients. Only the CANTAB was applied to the healthy control group; no other clinical evaluation scales were used. Neurocognitive tests were applied in a quiet room. Brief information about the battery's instructions was provided before each tests. The individuals were accompanied by a researcher, who also performed the tests. The tests were completed in approximately 1 hour and 45 minutes.

\section{Measures}

Sociodemographic Data Collection Form: This form was prepared by the authors of the current study to inquire and record the sociodemographic data of the participants.

Borderline Personality Inventory (BPI): The BPI was developed by Leichsenring (22) and adapted into Turkish in 2006 by Aydemir et al. (23). BPI is an inventory consisting of 53 items and answered as true or false. BPI covers all aspects of BPDs symptom patterns. The scale results are calculated over the total score, and the total correct number indicates the level of borderline personality organization. The cut-off point was determined as 20 with a validity and reliability study. 
Structured Clinical Interview for DSM-IV: Axis I Disorders (SCID-I): SCID-I is a semi-structured clinical interview tool developed to diagnose DSM-IV (Axis I) psychiatric disorders. The Turkish validity and reliability study of SCID-I was conducted by Ozkurkcugil et al. (24). It consists of six modules and investigates a total of 38 DSM-IV Axis I disorders according to diagnostic criteria. The application takes an average of 25-60 minutes.

Structured Clinical Interview for DSM-IV Axis II Personality Disorders (SCID-II): SCID-II is designed to question every criterion of avoidant, dependent, obsessive-compulsive, passive-aggressive, selfdefeating, paranoid, schizoid, histrionic, narcissistic, borderline, and antisocial personality disorders. The translation of SCID-II into Turkish was carried out by Coşkunol et al. (25).

Childhood Trauma Questionnaire (CTQ): The CTQ Scale was developed by Bernstein et al. (26). The Turkish validity and reliability study of the short version, which includes 28 items, was conducted in 2012 by Sar et al. (27). It is a 5-point Likert-type selfreport scale. It includes questions that assess childhood emotional, physical and sexual abuse, as well as physical and emotional neglect. The response options are given as (1) never, (2) rarely, (3) occasionally, (4) often, (5) very often. Each question is scored from 1 to 5 . It allows the calculation of individual traumatic experience subscales and a total score. The total score of the scale can range from 54-270.

Cambridge Neuropsychological Test Automated Battery (CANTAB): CANTAB is widely used all over the world, and has been used in more than 2400 peerreviewed international articles, and supports a large number of cognitive evaluation processes. As CANTAB tests are non-verbal, it is a practical tool for assessing cognitive functions for use in countries with different languages and cultures (28).

Cambridge Gambling Test (CGT): CGT is a computerized cognitive test that examines decisionmaking abilities. At the beginning of the test, a certain score is given to the patient by the computer and the person aims to increase this score. In one part of the test ('Ascending'), there is an increase from the smallest bet to the bigger bets until the patient selects one. In the second part of the test ('Decreasing'), a decrease from the largest bet to the smaller bet is made until the patient selects one. This test evaluates four performances, including the reasoning time, the time to decide which box the yellow icon is in, and with the appropriate response selection rate, the person's ability to make the most probable choice. The scale, therefore, evaluates decision-making behavior by excluding the learning status.

Emotion Recognition Test (ERT): ERT is a computerized cognitive test that examines emotion recognition through facial expressions. During the ERT test, the participants are asked to identify the emotions in the facial expressions that appear on the screen. After the start of the test, the participants are asked to look at the cross sign in the middle of the screen continuously so that the facial expression appearing on the screen can be detected more easily just in $250 \mathrm{~ms}$. After this, the facial expression disappears and six boxes appear on the screen: Anger, Disgust, Fear, Surprise, Happiness, and Sadness. The participants are asked to touch the box that best describes the emotion in the presented facial expression. The test consists of 2 blocks. Each block has a total of 90 facial expressions. Some expressions are easier to identify, while others are more difficult to identify. With this scale, the response latency times of the patients, the correct response rates for both total and each emotion, and the frequency of emotions chosen by the patients can be evaluated.

\section{Statistical Analysis}

The Statistical Package for the Social Sciences (SPSS) for Windows version 16.0 (Chicago, SPSS Inc.) was used to assess the findings obtained from the study. Descriptive statistical methods (average, standard deviation, frequency, percentage) were used to assess the study data. The compatibility of the variables to normal distribution was examined visually (histogram and probability graphics) and analytically (Kolmogorov-Smirnov and Shapiro-Wilk tests). Oneway analysis of variance (ANOVA) or the KruskalWallis test was used to compare the sociodemographic, clinical, and cognitive data of patients with and without CSA with healthy controls according to whether the data showed normal distribution. A homogeneity test was applied for the data with normal distribution and post-hoc tests were determined according to the homogeneity status. The Fisher's least significant difference (LSD) test was used for post-hoc comparisons of parametric data showing homogeneous distribution. The Bonferroni-corrected Mann-Whitney $U$ test was used for pairwise comparisons in post-hoc analyses of data that did not show normal distribution. The Bonferroni-corrected p-value was accepted as 0.017. Along with these, the Chi-square test was used for the comparison of categorical data. For correlation analysis, the Pearson's 
test was used when both data were normally distributed, and the Spearman's test was used when no data were parametric. A multivariate linear regression model was created to examine the types of trauma and decision-making abilities that affect BPI. Jamovi 1.0.7.0 and SPSS PROCESS Macro were used for mediation and moderation analysis. The results were evaluated at $95 \%$ confidence interval at significance $\mathrm{p}<0.05$.

\section{RESULTS}

\section{Description of Patients with BPD}

The mean age of the healthy group was $27.57 \pm 4.34$ years, 25.94 \pm 5.57 years in patients without CSA and $28.88 \pm 6.64$ years in patients with CSA. The healthy group included 5 males, the patient group without CSA had 2 males and the patients with CSA group did not include any male patients. Except for occupational status, no significant difference was found between the groups in terms of age, gender, education level, and marital status. The comparison of sociodemographic data of patients with BPD and healthy volunteers is shown in Table 1.

Twenty-two (61.1\%) BDP patients had self-mutilative behavior and $26(72.2 \%)$ attempted suicide. Seventeen (47.2\%) patients had previously been hospitalized. Sixteen (44.4\%) patients had received psychotherapy intervention. Nineteen (52.8\%) patients had a family history of psychiatric disease. The mean BPI score of the BPD group was $28.7 \pm 8.49$ (median: 30.0 ). The mean BPI scores of BDP patients with or without CSA were $31.72 \pm 5.78$ and $25.77 \pm 9.81$, respectively; this difference was statistically significant $(\mathrm{t}=-2.213, \mathrm{p}=0.034)$.

\section{Comparison of Cognitive Functions Between the Three Independent Groups}

The comparison of the ERT scores indicated that apart from fear recognition score $(\mathrm{p}=0.045)$, there was no significant difference between the groups in other emotion recognition scores. The comparison of the ERT scores of patients with BPD and healthy volunteers is shown in Table 2. The comparison of the CGT scores indicated that the proportion of risking at $10 \%$ chance of winning in the BPD with CSA group was significantly higher than the healthy control and BPD without CSA groups ( $p=0.002$ ). The comparison of the CGT scores of patients with BPD and healthy volunteers is shown in Table 3. A statistically significant correlation was found between the BPI and CSA scores $(r=0.32, p<0.05)$. The correlation between childhood trauma scale scores and BPI scores is shown in Table 4.

A multivariate linear regression model was created to investigate the effect of sexual abuse, physical neglect, and decision-making ability on BPI. Physical neglect and sexual abuse were found to have a significant effect on BPI (adjusted $\mathrm{R}^{2}=0.210, \mathrm{p}=0.014, \mathrm{~F}=4.106$ ). The investigation of the effects of sexual abuse, physical

\begin{tabular}{|c|c|c|c|c|c|}
\hline & $\begin{array}{l}\text { Healthy control } \\
\qquad(n=35)\end{array}$ & $\begin{array}{c}\text { BPD without CSA } \\
(n=18)\end{array}$ & $\begin{array}{l}\text { BPD with CSA } \\
(n=18)\end{array}$ & $F / \chi^{2}$ & $\mathbf{p}$ \\
\hline Age $(\text { Mean } \pm S D)^{a}$ & $27.57 \pm 4.34$ & $25.94 \pm 5.57$ & $28.88 \pm 6.64$ & 1.388 & 0.256 \\
\hline Gender ${ }^{\mathbf{b}}$ & & & & & 0.250 \\
\hline Female & $30(85.7 \%)$ & 16 (88.9\%) & $18(100 \%)$ & & \\
\hline Male & $5(14.3 \%)$ & $2(11.1 \%)$ & $0(0 \%)$ & 2.772 & \\
\hline Education level (mean $\pm s d) c$ & $\begin{array}{c}12.74 \pm 2.52 \\
\text { (median: } 13.00)\end{array}$ & $\begin{array}{c}12.00 \pm 2.08 \\
\text { (median: } 12.00 \text { ) }\end{array}$ & $\begin{array}{c}11.38 \pm 3.01 \\
\text { (median: } 12.00 \text { ) }\end{array}$ & 4.068 & 0.131 \\
\hline Marital status ${ }^{\mathbf{b}}$ & & & & & 0.056 \\
\hline Married & $12(34.3 \%)$ & $2(11.1 \%)$ & $4(22.2 \%)$ & & \\
\hline Single & $23(65.7 \%)$ & $15(83.3 \%)$ & $11(61.1 \%)$ & & \\
\hline Divorced & $0(0 \%)$ & $1(5.6 \%)$ & $3(16.7 \%)$ & 9.225 & \\
\hline \multicolumn{6}{|l|}{ Occupation } \\
\hline Employed & 29 ( $82.9 \%)$ & $7(38.9 \%)^{b-1}$ & $9(50 \%)^{b-1}$ & & 0.001 \\
\hline Unemployed & $0(0 \%)$ & $8(44.4 \%)$ & $7(38.9 \%)$ & & \\
\hline Student & 6 (17.1\%) & 3 (16.7\%) & 2 (11.1\%) & 19.322 & \\
\hline
\end{tabular}

${ }^{\mathrm{a} O n e}$ Way Anova was performed, ${ }^{\mathrm{b}} \mathrm{Chi}-\mathrm{Square}$ Test was performed. ${ }^{\mathrm{C} K r u s k a l}$ Wallis Test was performed. BPD: Borderline personality disorder, CSA: Childhood sexual abuse. Bonferroni correction was applied and $p$-value was taken as 0.017

${ }^{\mathrm{b}-1} \mathrm{p}<0.017$ (Compared to healthy control group) 
Table 2: Comparison of Emotion Recognition Test (ERT) scores of BPD patients and healthy volunteers

\begin{tabular}{|c|c|c|c|c|c|}
\hline ERT scores & $\begin{array}{l}\text { Healthy control } \\
\qquad(n=35)\end{array}$ & $\begin{array}{l}\text { BPD without CSA } \\
\qquad(n=18)\end{array}$ & $\begin{array}{l}\text { BPD with CSA } \\
\quad(n=18)\end{array}$ & $F / \chi^{2}$ & $\mathbf{p}$ \\
\hline Total correct (\%) & $67.53 \pm 6.97$ (med: 68.33) & $62.43 \pm 10.73$ (med: 66.94) & $61.08 \pm 14.44$ (med: 62.22) & 3.699 & 0.157 \\
\hline Correct happiness (\%) & 36.74 \pm 10.31 (med: 35.00$)$ & $34.88 \pm 11.75$ (med: 31.00$)$ & $31.16 \pm 10.34$ (med: 30.50) & 2.492 & 0.288 \\
\hline Correct sadness (\%) ${ }^{a}$ & $35.82 \pm 14.15$ (med: 32.00$)$ & 33.83 \pm 10.62 (med: 31.00$)$ & $36.22 \pm 14.48$ (med: 30.50$)$ & 0.090 & 0.956 \\
\hline Correct fear $(\%)^{b}$ & $26.8 \pm 7.39$ & $25.88 \pm 9.77$ & $33.55 \pm 14.6^{x, y}$ & 3.235 & 0.045 \\
\hline Correct anger $(\%)^{a}$ & $21.65 \pm 4.39$ (med: 22.00$)$ & 21.33 \pm 5.79 (med: 21.00$)$ & $25.77 \pm 11.56$ (med: 22.00$)$ & 1.280 & 0.527 \\
\hline Correct surprise (\%) & 32.71 \pm 7.24 (med: 31.00$)$ & $34.00 \pm 10.49$ (med: 34.00$)$ & $29.66 \pm 12.01$ (med: 29.50) & 1.148 & 0.563 \\
\hline Correct disgust (\%) ${ }^{a}$ & $26.25 \pm 8.85$ (med: 26.00$)$ & 30.05 \pm 14.01 (med: 29.00) & $23.61 \pm 11.90$ (med: 24.50$)$ & 1.674 & 0.433 \\
\hline
\end{tabular}

BPD: Borderline personality disorder. VMPT: Verbal Memory Process Test, CSA: Childhood sexual abuse

${ }^{a}$ Kruskal Wallis Test was performed. In the pairwise comparison of the data with significant differences in the Kruskal Wallis test, Bonferroni correction was applied and the $p$-value was taken as 0.017 .

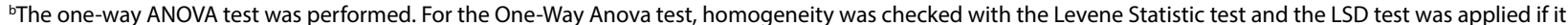
showed homogeneous distribution.

${ }^{x} \mathrm{p}<0.05$ (for LSD) or $\mathrm{p}<0.017$ (Compared to healthy control group)

${ }^{y} \mathrm{p}<0.05$ (Compared to BPD without CSA group)

Table 3: Comparison of Cambridge Gambling Test (CGT) scores of BPD patients and healthy volunteers

\begin{tabular}{|c|c|c|c|c|c|}
\hline CGT scores & $\begin{array}{c}\text { Healthy control } \\
(n=35)\end{array}$ & $\begin{array}{l}\text { BPD without CSA } \\
(n=18)\end{array}$ & $\begin{array}{l}\text { BPD with CSA } \\
\quad(n=18)\end{array}$ & $\chi^{2}$ & $\mathbf{p}$ \\
\hline Overall proportion of bet & $0.54 \pm 0.16$ (med: 0.50$)$ & $0.52 \pm 0.14$ (med: 0.51$)$ & $0.58 \pm 0.19$ (med: 0.55$)$ & 0.814 & 0.66 \\
\hline Proportion of bet at $50 \%$ chance & $0.45 \pm 0.24$ (med: 0.43 ) & $0.43 \pm 0.23$ (med: 0.40$)$ & $0.48 \pm 0.23$ (med: 0.50$)$ & 0.466 & 0.79 \\
\hline Proportion of bet at $60 \%$ chance & $0.51 \pm 0.20$ (med: 0.50$)$ & $0.45 \pm 0.23$ (med: 0.51$)$ & $0.55 \pm 0.22$ (med: 0.58$)$ & 1.742 & 0.42 \\
\hline Proportion of bet at $70 \%$ chance & $0.54 \pm 0.21$ (med: 0.51$)$ & $0.61 \pm 0.18$ (med: 0.57$)$ & $0.56 \pm 0.20$ (med: 0.53 ) & 1.270 & 0.53 \\
\hline Proportion of bet at $80 \%$ chance & $0.59 \pm 0.19$ (med: 0.61) & $0.58 \pm 0.18$ (med: 0.54$)$ & $0.59 \pm 0.22$ (med: 0.61) & 0.256 & 0.88 \\
\hline Proportion of bet at $90 \%$ chance & $0.65 \pm 0.20$ (med: 0.71$)$ & $0.60 \pm 0.20$ (med: 0.59$)$ & $0.60 \pm 0.21$ (med: 0.58$)$ & 1.575 & 0.45 \\
\hline Proportion of bet at $10 \%$ chance & $0.25 \pm 0.20$ (med: 0.25$)$ & $0.33 \pm 0.28$ (med: 0.25$)$ & $0.71 \pm 0.26$ (med: 0.75$)^{x, y}$ & 12.132 & 0.002 \\
\hline
\end{tabular}

BPD: Borderline personality disorder. CGT: Cambridge Gambling Test, CSA: Childhood sexual abuse

${ }^{a}$ Kruskal Wallis Test was performed. In the pairwise comparison of the data with significant differences in the Kruskal Wallis test, Bonferroni correction was applied and the $\mathrm{p}$-value was taken as 0.017 .

${ }^{\mathrm{x}} \mathrm{p}<0.017$ (Compared to healthy control group)

${ }^{y} \mathrm{p}<0.017$ (Compared to BPD without CSA group)

Table 4: The Correlation between Childhood Trauma Scale Scores and Borderline Personality Inventory Scores Emotional abuse Physical abuse Physical neglect Emotional neglect Sexual abuse Total trauma

\begin{tabular}{llllll}
\hline BPI scores & $0.33^{* a}$ & $0.25^{\mathrm{a}}$ & $0.33^{\mathrm{a}}$ & $0.30^{\mathrm{b}}$ & $0.32^{* \mathrm{~b}}$
\end{tabular}

${ }^{*} \mathrm{p} \leq 0.05, \mathrm{BPI}$ : Borderline Personality Inventory, ${ }^{\mathrm{a} S p e a r m e n(r h o)}$ correlation test was performed, ${ }^{\mathrm{b} P e a r s o n}$ correlation test was performed

Table 5: Investigation of the Effect of Sexual Abuse, Physical Neglect and Age on BPI Borderline Personality Inventory

\begin{tabular}{lccccc}
\cline { 2 - 5 } Independent variables & B & S.E. & Beta coefficient & 95.0\% C.1.for $\boldsymbol{\beta}$ coefficient & p \\
\hline Physical neglect & 1.115 & 0.461 & 0.365 & $0.176-2.055$ & $0.021^{*}$ \\
Sexual abuse & 0.380 & 0.181 & 0.318 & $0.011-0.749$ & $0.044^{*}$ \\
Overall proportion of bet & 10.075 & 6.563 & 0.233 & $-3.294-23.444$ & 0.135 \\
\hline
\end{tabular}

${ }^{*} \mathrm{p} \leq 0.05$, Multiple Linear Regression Analysis test was performed. Adjusted R square: 0.210, p=0.014, F:4.106, BPI: Borderline Personality Inventory, S.E: Standard error

neglect, and age on BPI is shown in Table 5. Several statistical programs (Jamovi 1.0.7.0 and SPSS Process Macro) were used for mediation and moderation analysis. No moderation or mediation relationship was found between CSA, cognitive functions, and API scores.

\section{DISCUSSION}

The present study was designed to evaluate the relationship between childhood maltreatment and the clinical presentation of BPD, previously shown in large- 
scale studies. The term childhood maltreatment is used for a wide range of situations including childhood trauma. The term was used in a fragmented form in previous studies, and one of its key components, CSA, has been further described and discussed in detail in this study. Additionally, we have examined the effect of CSA on cognitive functions in BPD along with the relationship between CSA, the clinical presentation of $\mathrm{BPD}$, and cognitive functions.

We report in this study that patients with BPD who experienced CSA have more severe disease. This finding is significant in both comparison and correlation analyses. In this context, the findings of our study support the results of previous studies examining the relationship between BPD and childhood maltreatment, more specifically the CSA. In fact, it has been emphasized that childhood maltreatment might be associated with BPD, as well as severe psychiatric disorders such as psychotic disorder (29) and mood disorder (30). Evaluating the relationship between CSA and psychiatric diseases, Hailes et al. (31) reported in a review that CSA had the strongest relationship with psychiatric conditions such as conversion disorder, BPD, anxiety disorder and depressive disorder, respectively. Early experiences with caregivers play an important role in the development of emotional and motivational regulation. Problems in related issues make it difficult for children to experience and control different emotional situations (32). In a study conducted by Seguin-Lemire et al. (33), it was stated that the ability for emotional regulation was weak, and patients exposed to severe traumatic experiences such as CSA experienced intense emotional lability. Emotional dysregulation causes patients with BPD to be more sensitive to environmental stimuli and to experience emotions more intensely than others, making them hypersensitive and overreactive (34). Emotional lability is associated with a rapid and unexpected change in people's emotions and moods (35). Emotional dysregulation and emotional lability have been reported to cause inability to cope with intense emotional stimuli, thus contributing to the development of selfinjuring behaviors and suicidal thoughts (36). Studies evaluating the effects of childhood traumas at the neurobiological level have suggested permanent disorders in corticotrophin-releasing hormone and other HPA axis-related hormones $(37,38)$. High stress levels may cause volume loss, decrease in neurogenesis, and epigenetic changes with methylation and demethylation reactions, especially in the hippocampal area $(37,39)$. Early traumatic experiences can create permanent sensitivity in nerve loops. In this context, it may be possible that early childhood traumas can worsen the behavioral and cognitive symptoms seen in the manifestation of BPD. Standard dialectical behavioral therapy (DBT), as well as modified DBT methods, can be used in the treatment of complex and severe traumas in patients with BPD (40). Addressing childhood traumas such as CSA, especially when working with patients with $\mathrm{BPD}$, may contribute significantly to the mitigation of feelings of shame and guilt, accepting the feelings related to the trauma experienced, and reducing self-harming behaviors $(41,42)$. Another important finding of the present study is that the betting rates of patients with exposure to CSA at the position of a $10 \%$ winning probability were higher than both healthy controls and BPD patients with no CSA. It has been reported that individuals with BPD have poor self-regulation and often make impulsive and risky decisions, rather than predictive or planned decisions (43). In fact, risky sexual behavior, substance abuse, and other reckless behaviors can be observed among individuals with BPD (44). Kulacoglu et al. (45) reported that sexually abused children experience more behavioral problems than children who did not have CSA. In a study evaluating decisionmaking abilities in patients with BPD by using the Iowa Gambling Test, it was reported that BPD patients made more disadvantageous decisions compared to the control group (46). In an animal study conducted by Dias-Ferreira et al. (47), mice exposed to chronic stress were insensitive to the changing reward paradigm and resistant to changing their choices. Likewise, it has been reported that patients with $\mathrm{BPD}$ were resistant to the learning with negative feedback (21). Chronic stress was shown to increase corticosteroid levels, causing medial prefrontal cortex atrophy, associative striatum atrophy, and sensorimotor striatum hypertrophy, which can be occur as a decision-making disorder (47). CSA has also been shown to cause dysfunction in the HPA axis, impaired feedback mechanism, and an increase in glucocorticoid levels (48). In this context, CSA is thought to cause disruptions in decision-making by inducing changes in relevant brain regions, similar to the structural changes caused by chronic stress in a developing organism. Although impaired decisionmaking/risk-taking behavior in BPD has been shown before, to the best of our knowledge, there is no study showing that experiencing CSA might increase risktaking behavior in this patient group. In this respect, we think that our findings make an important contribution to the literature. 
The ability of patients exposed to CSA to recognize the facial expression of fear accurately was found to be higher in this study than the healthy controls and BPD patients who were not exposed to CSA. Although the number of studies examining the effect of CSA on facial emotion recognition in patients with BPD is limited, there are studies conducted on patients with posttraumatic stress disorder (PTSD) and patients with other psychiatric conditions. In a study conducted with adolescents, it was shown that patients with PTSD recognized fear expressions more easily and their reaction time was shorter (49). The recognition of facial expressions begins to develop in early childhood, and the frequency of exposure to specific emotions is considered to be important in recognition abilities (50). It is known that traumatized children are less exposed to atypical and unexpected positive emotions and more intense and severe negative emotions (51). The hypervigilance of traumatized people in trauma-related conditions enables them to better identify dangerous situations. Thus, this process is a protective mechanism in case the individual is re-exposed to the trauma. However, these findings are not consistent in all studies. Ardizzi et al. (52) reported a study conducted with 31 street-children and 31 healthy controls in which exposure to maltreatment was seen to increase prejudice during the emotion recognition task and created a bias in favor of anger in the choices of the children. The same study suggested that street children tended to choose anger more, particularly over fear (52). However, since the study was not conducted on a patient group, it may have led to different outcomes. A study comparing three groups of individuals with a similar design to the current study; BDP patients with/ without CSA exposure and healthy controls showed that the BPD patients with a history of sexual abuse were more sensitive to recognize fear (53). The tendency to be more susceptible to recognizing certain emotions in different situations may be related to the familiarity with the emotional load that people are exposed to or experience in their external environment.In the current study, no moderator role was identified in the relationship between CSA, worsening cognitive deficits, and the clinical presentation of BPD. Similarly, no mediator role of cognitive functions was found in the relationship between CSA and the clinical presentation of BPD. The absence of this significant relationship was most likely since our sample size did not have enough power for regression analysis.

The study has few limitations to consider when evaluating the results. The relatively small sample size of the present study is one of the limitations of the research. Although patients with low intelligence or cognitive deficits were excluded through a psychiatric interviews, the lack of a detailed IQ examination can be considered as another limitation. Yet another limitation is that a significant proportion of patients were receiving either psychotherapy or psychopharmacological treatment. Despite these limitations, the current study supports an important idea that the evaluation of CSA improves the diagnostic validity of BPD.

In conclusion, the current study suggests that CSA has significant effects on the clinical presentation and neurocognitive profiles of BPD. In this context, our study once again emphasizes the importance of investigating childhood maltreatment, especially CSA in patients with BPD. CSA leads to deficiencies such as risky decision-making and aberrant emotion recognition processes. Therefore, necessary interventions conducted in the context of CSA may play an important role in personalized treatment approaches. This, in turn, may provide more effective treatment with a rapid response. However, the mediation and moderation relationships need to be further evaluated in studies with larger sample sizes.

\begin{tabular}{|c|c|c|}
\hline \multicolumn{2}{|c|}{ Contribution Categories } & \multirow{2}{*}{$\begin{array}{l}\text { Author Initials } \\
\text { S.G., B.K., M.Y.G. }\end{array}$} \\
\hline \multirow{3}{*}{ Category 1} & Concept/Design & \\
\hline & Data acquisition & B.K. \\
\hline & Data analysis/Interpretation & S.G., H.G. \\
\hline \multirow{2}{*}{ Category 2} & Drafting manuscript & S.G., A.T.A., B.K. \\
\hline & Critical revision of manuscript & M.Y.G., H.G. \\
\hline Category 3 & Final approval and accountability & M.Y.G., B.K., A.T.A., S.G., H.G. \\
\hline \multirow{2}{*}{ Other } & Technical or material support & S.G. \\
\hline & Supervision & M.Y.G., H.G. \\
\hline
\end{tabular}

Acknowledgement: We would like to thank Mehmet Kavaklı for sharing his knowledge in conducting and interpreting the statistical analyses.

Ethics Committee Approval: Ethical approval for the study was obtained from the Erenkoy Neurological and Mental Health Training and Education Hospital Clinical Research Ethic Committee (IRB Date/Number: 01.06.2015/11).

Informed Consent: The patients were informed about the research and each agreed to give informed consent for participate in the study.

Peer-review: Externally peer-reviewed.

Conflict of Interest: The authors declare no conflict of interest with respect to the research, authorship, or publication of this article. The authors are responsible for the content and writing of the manuscript.

Financial Disclosure: This research did not receive any specific grant from funding agencies in the public, commercial, or not-forprofit sectors. 


\section{REFERENCES}

1. Grant BF, Chou SP, Goldstein RB, Huang B, Stinson FS, Saha TD, et al. Prevalence, correlates, disability, and comorbidity of DSM-IV borderline personality disorder: Results from the Wave 2 National Epidemiologic Survey on Alcohol and Related Conditions. J Clin Psychiatry 2008; 69:533-545. CrossRef]

2. Black DW, Blum N, Pfohl B, Hale N. Suicidal behavior in borderline personality disorder: Prevalence, risk factors, prediction, and prevention. J Pers Disord 2004; 18:226-239. [CrossRef]

3. Duque-Alarcón X, Alcalá-Lozano R, González-Olvera JJ, GarzaVillarreal EA, Pellicer F. Effects of childhood maltreatment on social cognition and brain functional connectivity in Borderline Personality Disorder patients. Front Psychiatry 2019; 10:156.

4. Gunderson JG. Borderline personality disorder: Ontogeny of a diagnosis. Am J Psychiatry 2009; 166:530-539.

5. Hastrup LH, Jennum P, Ibsen R, Kjellberg J, Simonsen E. Societal costs of borderline personality disorders: a matched-controlled nationwide study of patients and spouses. Acta Psychiatr Scand 2019; 140:458-467. [CrossRef]

6. Bornstein RF, Becker-Matero N, Winarick DJ, Reichman AL. Interpersonal dependency in borderline personality disorder: Clinical context and empirical evidence. J Pers Disord 2010; 24:109-127. CrossRef

7. Porter C, Palmier-Claus J, Branitsky A, Mansell W, Warwick $\mathrm{H}$, Varese F. Childhood adversity and borderline personality disorder: A meta-analysis. Acta Psychiatr Scand 020; 141:6-20.

8. Martins CMS, de Carvalho Tofoli SM, Von Werne Baes C, Juruena M. Analysis of the occurrence of early life stress in adult psychiatric patients: A systematic review. Psychol Neurosci 2011; 4:219-227. CrossRef]

9. de Aquino Ferreira LF, Queiroz Pereira FH, Neri Benevides AML, Aguiar Melo MC. Borderline personality disorder and sexual abuse: A systematic review. Psychiatry Res 2018; 262:70-77. CrossRef

10. Merza K, Gábor P, Ildikó Kuritárné S. The role of childhood traumatization in the development of borderline personality disorder in Hungary. Eur J Psychiatry 2015; 29:105-118 CrossRef]

11. Carr CP, Martins CM, Stingel AM, Lemgruber VB, Juruena MF. The role of early life stress in adult psychiatric disorders: A systematic review according to childhood trauma subtypes. J Nerv Ment Dis 2013; 201:1007-1020. CrossRef]

12. Winsper C, Lereya ST, Marwaha S, Thompson A, Eyden J, Singh SP. The aetiological and psychopathological validity of borderline personality disorder in youth: A systematic review and metaanalysis. Clin Psychol Rev 2016; 44:13-24.

13. Turniansky H, Ben-Dor D, Krivoy A, Weizman A, Shoval G. A history of prolonged childhood sexual abuse is associated with more severe clinical presentation of borderline personality disorder in adolescent female inpatients - A naturalistic study. Child Abuse Negl 2019; 98:104222. CrossRef]

14. Bazanis E, Rogers RD, Dowson JH, Taylor P, Meux C, Staley C, et al. Neurocognitive deficits in decision-making and planning of patients with DSM-III-R borderline personality disorder. Psychol Med 2002; 32:1395-1405 [CrossRef]
15. Dinn WM, Harris CL, Aycicegi A, Greene PB, Kirkley SM, Reilly C. Neurocognitive function in borderline personality disorder. Prog Neuropsychopharmacol Biol Psychiatry 004; 28:329-341.

16. O'Leary KM, Brouwers P, Gardner DL, Cowdry RW. Neuropsychological testing of patients with borderline personality disorder. Am J Psychiatry 1991; 148:106-111. CrossRef]

17. Ruocco AC. The neuropsychology of borderline personality disorder: a meta-analysis and review. Psychiatry Res 2005;137:191202. [rossRef]

18. Svaldi J, Philipsen A, Matthies S. Risky decision-making in borderline personality disorder. Psychiatry Res 012;197:112-118.

19. Daros AR, Zakzanis KK, Ruocco AC. Facial emotion recognition in borderline personality disorder. Psychol Med 2013;43:19531963. [CrossRef]

20. Fertuck EA, Fischer S, Beeney J. Social cognition and borderline personality disorder: Splitting and trust impairment findings. Psychiatr Clin North Am 2018; 41:613-632. [CrossRef]

21. Kaplan B, Yazici Gulec M, Gica S, Gulec H. The association between neurocognitive functioning and clinical features of borderline personality disorder. Braz J Psychiatry 2020; 42:503509. [rossRef]

22. Leichsenring F. Development and first results of the Borderline Personality Inventory: A self-report instrument for assessing borderline personality organization. J Pers Assess 1999; 73:45-63.

23. Aydemir O, Demet MM, Danaci AE, Deveci A, Taskin EO, Mizrak S, et al. Adaptation into Turkish, reliability and validity of Borderline Personality Inventory. Psychiatry in Türkiye 2006; 8:6-10. [Turkish]

24. Ozkurkcugil A, Aydemir O, Yildiz M, Esen DA, Koroglu E. Adaptation into Turkish and Reliability of Structured Clinical Interview for DSM-IV. Ilac ve Tedavi Dergisi 1999, 12:233-236. [Turkish]

25. Coşkunol H, Bagdiken I, Sorias S, Saygili R. Reliability of SCIDII (Turkish version) interview in personality disorders. Turkish Journal of Psychology 1994; 9:26-29.

26. Bernstein DP, Fink L, Handelsman L, Foote J, Lovejoy M, Wenzel $\mathrm{K}$, et al. Initial reliability and validity of a new retrospective measure of child abuse and neglect. Am J Psychiatry 1994; 151:1132-1136. CrossRef]

27. Sar V, Ozturk E, Ikikardes E. Validity and reliability of the Turkish Version of Childhood Trauma Questionnaire. Turkiye Klinikleri 2012; 32:1054-1063. [Turkish] CrossRef]

28. Luciana M, Nelson CA. Assessment of neuropsychological function through use of the Cambridge Neuropsychological Testing Automated Battery: Performance in 4- to 12-year-old children. Dev Neuropsychol 2002; 22:595-62 .[CrossRef]

29. Varese F, Smeets F, Drukker M, Lieverse R, Lataster T, Viechtbauer $\mathrm{W}$, et al. Childhood adversities increase the risk of psychosis: A meta-analysis of patient-control, prospective- and cross-sectional cohort studies. Schizophr Bull 2012; 38:661-671. CrossRef

30. Dale O, Sethi F, Stanton C, Evans S, Barnicot K, Sedgwick R, et al. Personality disorder services in England: Finding from a national survey. BJPsych Bull 2017; 41:247-253. [CrossRef] 
31. Hailes HP, Yu R, Danese A, Fazel S. Long-term outcomes of childhood sexual abuse: An umbrella review. Lancet Psychiatry 2019; 6: 830-839. CrossRef

32. Bradley R, Westen D. The psychodynamics of borderline personality disorder: A view from developmental psychopathology. Dev Psychopathol 2005;17:927-957. [CrossRef]

33. Séguin-Lemire A, Hébert $M$, Cossette L, Langevin R. A longitudinal study of emotion regulation among sexually abused preschoolers. Child Abuse Negl 2017; 63:307-316. [CrossRef]

34. Miano A, Grosselli L, Roepke S, Dziobek I. Emotional dysregulation in borderline personality disorder and its influence on communication behavior and feelings in romantic relationships. Behav Res Ther 2017; 95:148-157. [CrossRef]

35. Schoenleber M, Berghoff CR, Tull MT, DiLillo D, MessmanMoore T, Gratz KL. Emotional lability and affective synchrony in borderline personality disorder. Personal Disord 2016; 7:211220. [CrossRef]

36. Aaltonen KI, Rosenström T, Baryshnikov I, Karpov B, Melartin $\mathrm{T}$, Suominen K, et al. Mediating role of borderline personality disorder traits in the effects of childhood maltreatment on suicidal behaviour among mood disorder patients. Eur Psychiatry 2017; 44:53-60. CrossRef]

37. Heim C, Shugart M, Craighead WE, Nemeroff CB. Neurobiological and psychiatric consequences of child abuse and neglect. Dev Psychobiol 2010; 52:671-690 [CrossRef]

38. Nemeroff CB. Neurobiological consequences of childhood trauma. J Clin Psychiatry 2004; 65(Suppl.1):18-28.

39. Lupien SJ, McEwen BS, Gunnar MR, Heim C. Effects of stress throughout the lifespan on the brain, behaviour and cognition. Nat Rev Neurosci 2009; 10:434-445. CrossRef]

40. Choi-Kain LW, Finch EF, Masland SR, Jenkins JA, Unruh BT. What works in the treatment of borderline personality disorder. Curr Behav Neurosci Rep 2017; 4:21-30. CrossRef]

41. Bohus M, Dyer AS, Priebe K, Krüger A, Kleindienst N, Schmahl $\mathrm{C}$, et al. Dialectical behaviour therapy for post-traumatic stress disorder after childhood sexual abuse in patients with and without borderline personality disorder: A randomised controlled trial. Psychother Psychosom 2013; 82:221-233. [CrossRef]

42. Harned MS, Korslund KE, Linehan MM. A pilot randomized controlled trial of dialectical behavior therapy with and without the dialectical behavior therapy prolonged exposure protocol for suicidal and self-injuring women with borderline personality disorder and PTSD. Behav Res Ther 2014;55:7-17. [CrossRef]

43. Bountress K, Adams ZW, Gilmore AK, Amstadter AB, Thomas S, Danielson CK. Associations among impulsivity, trauma history, and alcohol misuse within a young adult sample. Addict Behav 2017; 64:179-184. CrossRef]

44. Barker V, Romaniuk L, Cardinal RN, Pope M, Nicol K, Hall J. Impulsivity in borderline personality disorder. Psychol Med 2015; 45:1955-1964.[CrossRef]

45. Kulacoglu F, Solmaz M, Ardic FC, Akin E, Kose S. The relationship between childhood traumas, dissociation, and impulsivity in patients with borderline personality disorder comorbid with ADHD. Psychiatry and Clinical Psychopharmacology 2017; 27:393-402. CrossRef]

46. Zegarra-Valdivia JA, Chino Vilca BN. Social cognition and executive function in borderline personality disorder: evidence of altered cognitive processes. Salud Ment 2019; 42:33-41. CrossRef]

47. Dias-Ferreira E, Sousa JC, Melo I, Morgado P, Mesquita AR, Cerqueira JJ, et al. Chronic stress causes frontostriatal reorganization and affects decision-making. Science 2009; 325:621-625. CrossRef

48. Mello MF, Faria AA, Mello AF, Carpenter LL, Tyrka AR, Price LH. Childhood maltreatment and adult psychopathology: Pathways to hypothalamic-pituitary-adrenal axis dysfunction. Braz J Psychiatry 2009; 31 (Suppl.2):S41-48.

49. Masten CL, Guyer AE, Hodgdon HB, McClure EB, Charney DS, Ernst M, et al. Recognition of facial emotions among maltreated children with high rates of post-traumatic stress disorder. Child Abuse Negl 2008; 32:139-153. CrossRef]

50. Beale JM, Keil FC. Categorical effects in the perception of faces. Cognition 1995; 57:217-239. [CrossRef]

51. Herrenkohl RC, Herrenkohl EC, Egolf BP, Wu P. The developmental consequences of child abuse: The Lehigh longitudinal study: In Starr RH, Wolfe DA (editors). The effects of child abuse and neglect: Issues and research. New York: Guilford Press, 1991, 57-81.

52. Ardizzi M, Martini F, Umiltà MA, Evangelista V, Ravera R, Gallese V. Impact of childhood maltreatment on the recognition of facial expressions of emotions. PLoS One 2015:10:e0141732.

53. Wagner AW, Linehan MM. Facial expression recognition ability among women with borderline personality disorder: implications for emotion regulation? J Pers Disord 1999; 13:329-344. CrossRef 